【論文】

\title{
波長選択性を有した $\mathrm{TiO}_{2}$ ナノ粒子群機能膜の ふく射特性に関する研究 \\ Radiative Properties of Wavelength Selection Coatings Pigmented with $\mathrm{TiO}_{2}$ Nanoparticles
}

\author{
江目 宏樹* メディ バネシ** 小宮 敦樹** 円山 重直**
} Hiroki GONOME, Mehdi BANESHI, Atsuki KOMIYA, and Shigenao MARUYAMA

\begin{abstract}
本研究では, 可視光の反射をおさえ近赤外光の反射を増加させるという波長選択性を有する機能膜 に関して, ナノ粒子として $\mathrm{TiO}_{2}$ を用いた機能膜を異なる粒径分布，体積分率，機能膜の膜厚において 作成し, 可視，近赤外領域の拡散反射率を測定した。 また，機能膜の粒径分布に関して理論解析を行 った．スペクトル反射率に対する粒子の粒径分布，体積分率，機能膜の膜厚の影響を示した．粒子の 粒径分布は反射率の波長依存性に関係し, 機能膜の体積分率と膜厚は反射率の大きさに影響すること を示した。
\end{abstract}

This study concerns about nanoparticles pigmented coatings used in controlling the radiative properties of surfaces exposed to sunlight. The desired coatings increase the near infrared reflectance while decreasing the reflectance of visible light. Both experimental and numerical approaches are followed in achieving desired spectral behavior. For this study the pigmented coatings are made using $\mathrm{TiO}_{2}$ as dispersed particles, clear acryl synthetic as matrix, and standard black paper as substrate. The spectral reflectance is measured by spectroscopy in visible and near infrared regions. The effects of the size distribution and volume fraction of pigment particles and coating thickness on spectral reflectance of pigmented coatings are analyzed in this study.

[Keywords: Radiative properties, Radiation, Coating, Nanoparticles, Titanium dioxide]

\section{1.はじめに}

自動車や住宅の屋根などの建築物外壁は通常，太陽光 に曝されており，これらには美的観点から黒などの暗い 色調が多用されてきた。しかしながら，これらの色を有 する表面は太陽光に対する可視光領域(VIS) と近赤外領域 (NIR)の吸収率が大きいため, 夏期の室内温度が上昇しや すく, 冷房負荷を増大させる原因となっている ${ }^{[1]}$. 一方, 省エネルギーの観点から, 太陽光を良好に反射する白色 塗料を表面に塗布すると，太陽光のエネルギー吸収を低 減し，室内の加熱を防ぐことが可能であるが，これらの 塗料はVIS の反射が大きく，照り返しの眩しさや，住宅

* 東北大学工学研究科機械システムデザイン工学専攻,

厂980-8579 仙台市青葉区荒巻字青葉 6-6.

Dept. of Mech., Systems and Design, Graduate School of Eng., Tohoku University, 6-6, Aramaki Aza Aoba, Aoba-ku, Sendai, Miyagi 980-8579.

FAX: 022-217-5244 E-mail: hiroki1006@pixy.ifs.tohoku.ac.jp

** 東北大学流体科学研究所, $\bar{\top} 980-8577$ 仙台市青葉区片平 2-1-1.

Institute of Fluid Science, Tohoku University, 2-1-1, Katahira, Aoba-ku, Sendai, Miyagi 980-8577.
家屋の美観を損ねる欠陥を有していた。またこれらの 白色塗料は污れに対しても弱いことが考えられる.

このため，VIS の反射を抑え，太陽光エネルギーの約 $52 \%$ 有する NIR の反射を促進させるという波長選択性 を有する機能膜が望まれている. 機能膜の模式図を Fig. 1 に示す．波長選択性を有する機能膜の例として，遮熱塗 料が挙げられる. 長岡ら ${ }^{[2]}$ は高反射率塗料の黒色顔料に おいて環境に配慮したクロムフリーの塗膜について研究 を行っている．長岡らの研究では物質のスペクトル特性 によって顔料に波長選択性を持たせている。一方で,

Baneshi ら ${ }^{[3]}$ はナノ粒子の粒子径, 粒径分布及び粒子密度 などを最適化することにより，ふく射制御可能な機能膜 に関する解析を行ってきた。

本研究では, Baneshi $5^{[3]}$ の解析結果に基づき, ナノ粒 子として $\mathrm{TiO}_{2}$ を使用し，波長選択性を有したナノ粒子群 機能膜を作成することを目的としている．機能膜実現の ためには, 膜厚, 粒子密度, $\mathrm{TiO}_{2}$ 粒子群の粒径分布など を最適化する必要がある，そこで， $\mathrm{TiO}_{2}$ 粒子群の粒径分 布，機能膜の体積分率を変化させ，機能膜の簡易型サン プルを作成し，拡散反射率を測定することでそれらのパ 
ラメータの与える影響について評価を行った。また，パ ラメータの中で粒子の粒径分布に着目し, 機能膜の反射 率に与える影響に関して理論解析を行った。また, 機能 膜の色を定量的に評価するため色計算を行った。

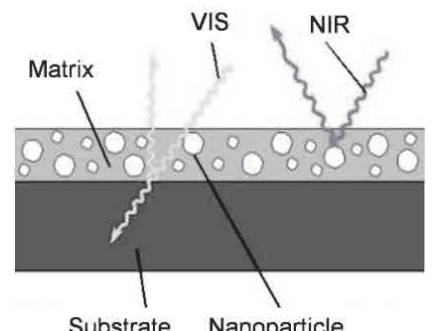

Fig. 1 Concept of a functional film

\section{2. 実 験}

\section{1 機能膜の作成}

$\mathrm{TiO}_{2}$ 粒子を透明なアクリル合成樹脂系塗料に懸濁させ, 機能膜の簡易型サンプルを作成した. $\mathrm{TiO}_{2}$ 粒子には異な った粒径分布を有するテイカ(株)製品の平均径 $0.646 \mu \mathrm{m}$ の JR-1000 と平均径 $0.175 \mu \mathrm{m}$ の JR-800 という二種類のル チル型 $\mathrm{TiO}_{2}$ を用いた。 JR-1000 及び JR-800 のカタログデ 一タによる粒径分布を Fig. $2^{[4]}$ に示寸.

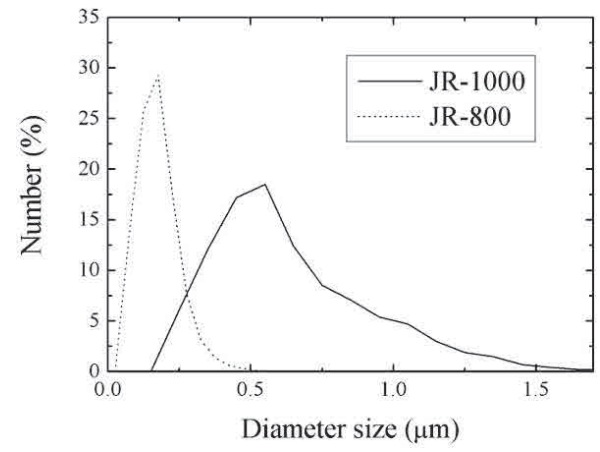

Fig. 2 Size distributions of each $\mathrm{TiO}_{2}{ }^{[4]}$

また, 粒子の機能膜に占める割合を表すため, 体積分率 $f_{v}$ を次式で定義した.

$$
f_{v}=\frac{\left(x_{t} / \rho_{x}\right)}{\left(x_{t} / \rho_{x}\right)+V_{y}}
$$

ここで $x_{t}[\mathrm{~g}]$ は $\mathrm{TiO}_{2}$ 粒子の混入量, $\rho_{x}\left[\mathrm{~g} / \mathrm{m}^{3}\right]$ は $\mathrm{TiO}_{2}$ の密度, $V_{y}\left[\mathrm{~m}^{3}\right]$ はアクリル合成樹脂系塗料の体積を示寸. 作成した 簡易型サンプルを TP 技研(株)の黒色隠・゚い率試験紙に遊 星回転法で塗布し反射率測定基板サンプルを作成した. ここで，隠ぺい率試験紙とは塗料が基板の色を隠すかを 評価する際に用いる紙のことである。 また, 遊星回転法
とは基板を回転させ，その遠心力で余分な塗膜を飛散さ せることで等膜厚面を作る塗布法である，基板を一定時 間で乾燥した後，デジタルマイクロメーターで機能膜の 膜厚 $t$ を測定した. 作成したサンプルの各パラメータを Table 1 に示寸.ここで, Sample 1 は膜を塗布していない 黒色基板である. また，作成した機能膜を Fig. 3 亿示す. 色むらを考慮して○で示した点で反射率を測定する.

Table 1 Specification of the functional coating samples

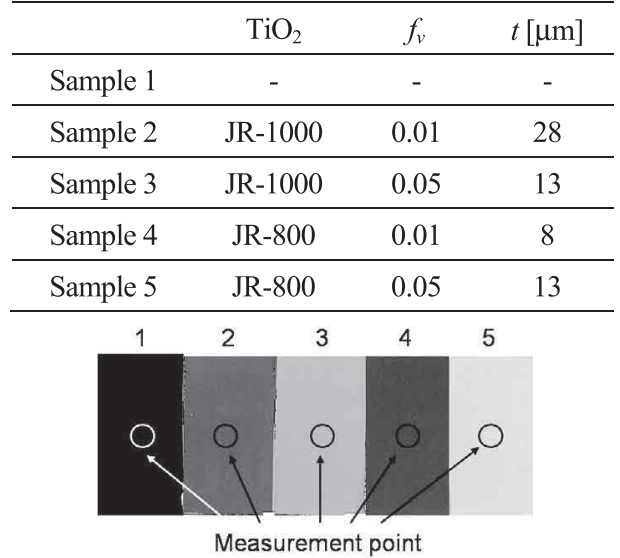

Fig. 3 Functional film

\section{2 測定}

作成した各 Sample の拡散反射率を波長範囲 200 $2500 \mathrm{~nm}$ の紫外線領域(UV)から NIR まで測定した. 本研究 では特に VIS と NIR について考察を行った。測定には Perkin Elmer社製紫外可視近赤外分光高度計 LAMBDA900 と Spectralon でコーティングされた積分球を用いた。 Spectralon はUV から NIR においてほぼ 100\%の反射率を 持ち，反射率の基準として使用した．測定装置の概略図 を Fig. 4 を示す.

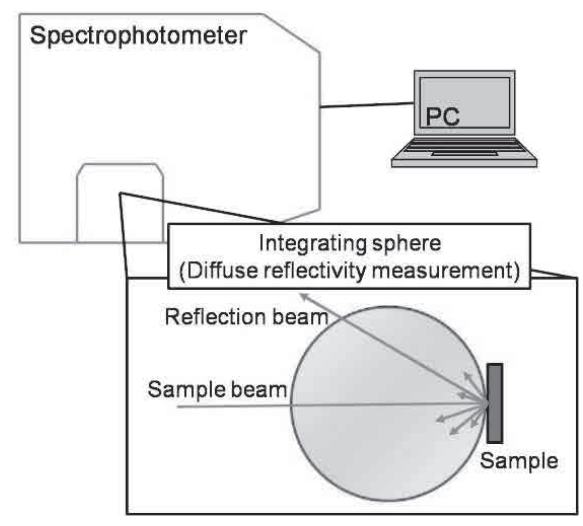

Fig. 4 Schematic of experiment device 


\section{3．測定結果および考察}

\section{1 粒径分布の依存性}

まず， $\mathrm{TiO}_{2}$ 粒子群の粒径分布の影響についての評価を 行った. 体積分率 $f_{v}=0.01$ とした機能膜の反射率測定結果 を Fig. 5 に, 体積分率 $f_{v}=0.05$ とした機能膜の反射率測定 結果を Fig. 6 に示す. 両図とも, UV 領域において反射率 が急激に減少しているが，これは $\mathrm{TiO}_{2}$ 粒子が UV 領域の 光を吸収するためである. Figure 5 を見ると, 小さい粒子 を用いた Sample 4 は Sample 2 よりも膜厚が小さいにも関 わらず, 波長 $400 \mathrm{~nm}$ で Sample 2 と同程度まで反射率が急 激に上昇し, 長波長になるにつれて反射率が急激に減少 している. それに対し，大きい粒子を用いた Sample 2 は 長波長になるにつれて反射率がゆるやかに減少している. ここで, $\mathrm{Mie}$ 散乱理論を用いて解いた $\mathrm{TiO}_{2}$ 粒子の後方散 乱効率において, 入射波長と粒径を変えた時の值の変化 を Fig. 7 で示寸. 後方散乱効率は次式で定義される.

$$
Q_{b a c k, s c a}=\frac{1-a_{1} / 3}{2} Q_{s c a}, \quad a_{1}=\frac{3}{2} \int_{-1}^{1} \Phi_{\lambda}(\mu) \mu \mathrm{d} \mu(2)
$$

ここで $Q_{b a c k, s c a[}\left[\right.$ - ] は後方散乱効率, $a_{1}[$ - $]$ は前方散乱パラメ 一タ, $Q_{s c a}[-]$ は散乱効率, $\Phi_{\lambda}[-]$ は位相関数, $\mu[-]$ は $\mu=\cos \theta$ で定義される変数を表している ${ }^{[3]}$. ここで NIR に着目寸ると粒径の大きい粒子の後方散乱効率が小粒径 の粒子のそれよりも大きくなっていることがわかる.こ のことから，より大きな粒径を有する $\mathrm{TiO}_{2}$ 粒子群を用い ることで NIR において高い反射率を示すことができると 推測できる. Figure 6 に示されるように VIS においては Sample 5 が Sample 3 に比べ, 急激に反射率が上昇してい ることがわかる。これは JR-800 が JR-1000 に比べて粒径 が小さいため体積分率一定ではふく射に作用寸る散乱断 面積が大きくなり定量的に反射率が大きくなるものと考 えられる. また, Fig. 6 においても小さい粒子を用いた

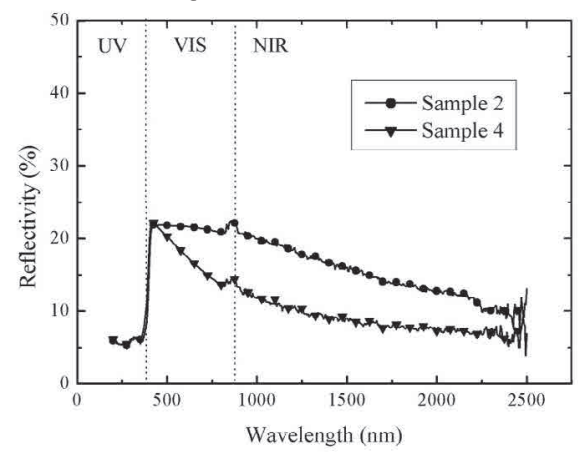

Fig. 5 Measurement results of diffuse reflectivities of $\mathrm{TiO}_{2}$ coating $f_{v}=0.01$

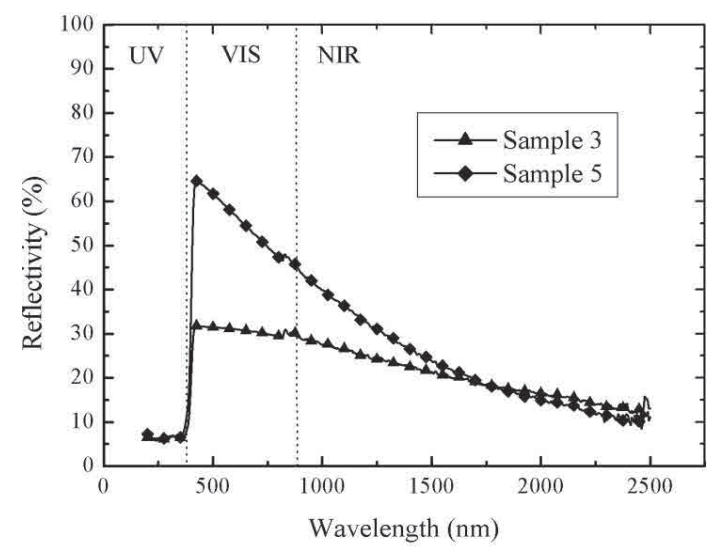

Fig. 6 Measurement results of diffuse reflectivities of $\mathrm{TiO}_{2}$ coating $f_{v}=0.05$

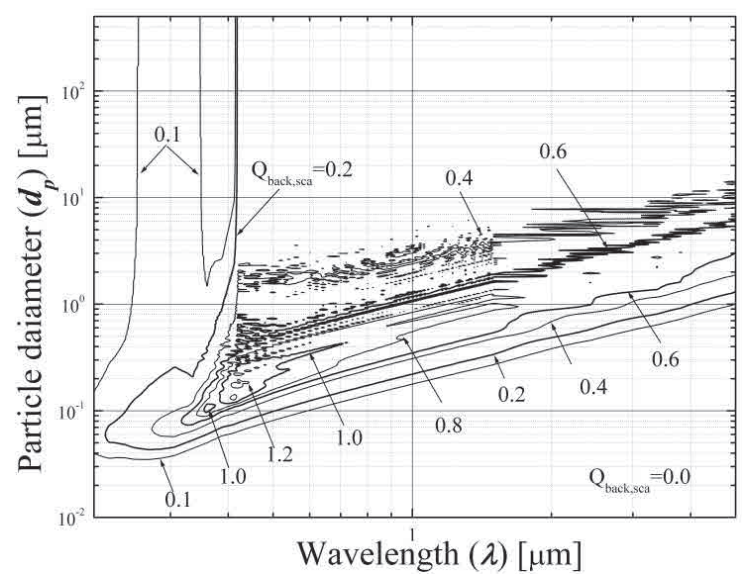

Fig. 7 Backscattering efficiency of $\mathrm{TiO}_{2}$ particle ${ }^{[3]}$

Sample 5 はVIS で反射率が急激に増加し, 長波長になる につれて反射率が減少している．以上のことから粒径分 布が拡散反射率の波長依存性に影響することがわかる.

\section{2 体積分率の依存性}

次に, 機能膜の体積分率の影響について評価を行った. ナノ粒子として JR-1000を用いた機能膜の反射率測定結 果を Fig. 8 に，ナノ粒子として JR-800を用いた結果を Fig. 9 に示寸. Figure 8 及び Fig. 9 より, Sample 1 と他の各 Sample の反射率を比較すると機能膜を塗布することで VIS，NIR ともに反射率が増加していることがわかる．ま た，両図とも機能膜の体積分率が増加するにつれて反射 率も増加している。これはナノ粒子の混入量が増えたこ とにより，ふく射に対する散乱断面積が増えたことによ るものと考えられる. 


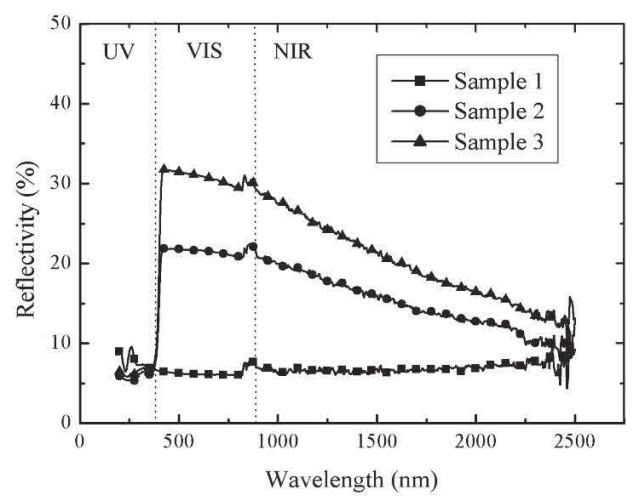

Fig. 8 Measurement results of diffuse reflectivities of $\mathrm{TiO}_{2}$ coating using JR- 1000

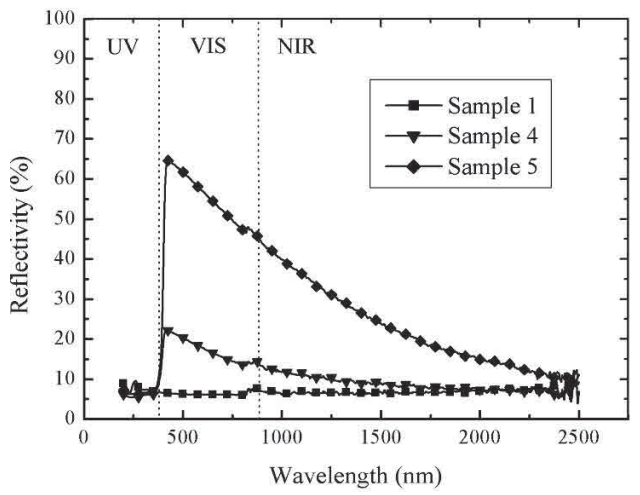

Fig. 9 Measurement results of diffuse reflectivities of $\mathrm{TiO}_{2}$ coating using JR-800

\section{4. 解 析}

実験から波長選択性に関して重要なパラメータは粒径 分布であることが示唆された. Baneshi らは単分散粒子の 粒径の影響について解析を行っている ${ }^{[3]}$. しかし，実際は 単分散粒子を作製することは困難である。 そこで反射率 に対する粒径分布の影響に関して評価を行うため, 機能 膜に関して理論解析を行った. Baneshi $ら^{[3]}$ の解析には光 線放射モデルによるふく射要素法 $\left(\mathrm{REM}^{2}\right)^{[5]}$ を用いている. REM $^{2}$ には Fig. 10 に示寸ような一次元平行平板系の解析 モデルを用いる. 一次元平行平板系のふく射輸送方程式 は次式で表される.

$$
\begin{aligned}
\frac{\mathrm{d} I_{\lambda}\left(x_{d}, \mu\right)}{\mathrm{d} S}=\beta\left[-I_{\lambda}\left(x_{d}, \mu\right)\right. & +(1-\omega) I_{b, \lambda}(T) \\
& \left.+\frac{\omega}{2} \int_{-1}^{1} I_{\lambda}\left(x_{d}, \mu^{\prime}\right) \Phi_{\lambda}\left(\mu^{\prime}\right) \mathrm{d} \mu^{\prime}\right]^{(3)}
\end{aligned}
$$

ここで, $I_{\lambda}\left[\mathrm{W} /\left(\mathrm{m}^{2} \cdot \mathrm{sr}\right)\right]$ は入射ふく射強度, $S[\mathrm{~m}]$ は入射ふく 射経路, $\beta[1 / \mathrm{m}]$ は減衰係数, $\omega[-]$ はアルベド, $I_{b, \lambda}\left[\mathrm{W} /\left(\mathrm{m}^{2}\right.\right.$.

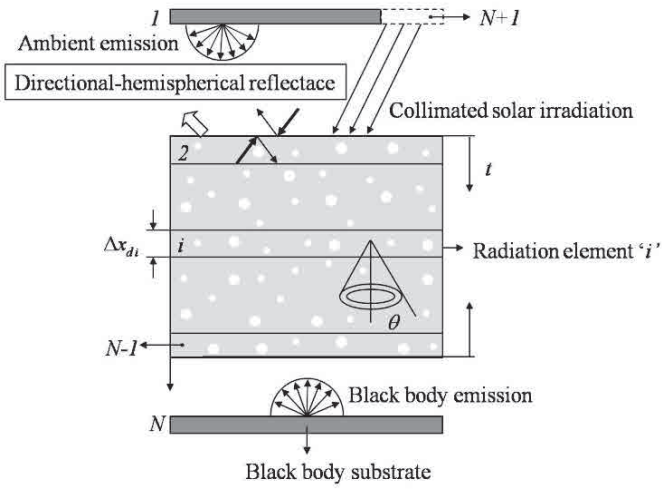

Fig. 10 Analysis model of a pigmented coating used by $\mathrm{REM}^{2}$ with collimated irradiation

sr)]は黒体ふく射強度を表している，まず，多分散系とし て Fig. 2 に表される粒径分布を導入し, 解析の精度につい て検討を行った，その後，様々な粒径分布に関して理論 解析を行い，NIR に反射率のピークが存在するように最 適な多分散系の粒径分布の検討を行った.

解析における粒径分布は次式で表される粒径分布関数 で表される ${ }^{[6]}$.

$$
n\left(d_{p}\right)=a d_{p}^{\alpha} \exp \left(-b d_{p}^{\gamma}\right), \quad 0 \leq d_{p}<\infty
$$

ここで, $\alpha, \gamma$ は粒子群の種類, 分布条件等により決まる值 であり, $a$ は数密度によって定められ, $b$ は粒子群の平均 径によって定められる正の実数である。この粒径分布関 数により，様々な平均径を表すことができる. 本研究で は体面積平均径またはS Sauter 径と呼ばれる平均径 $d_{32}$ を表 す. Sauter 径 $d_{32}$ は次式で定義される．また，本研究で用 いた粒径分布関数を Fig. 11 に示寸.

$$
d_{32}=\int_{0}^{\infty} n\left(d_{p}\right) d_{p}^{3} d d_{p} / \int_{0}^{\infty} n\left(d_{p}\right) d_{p}^{2} d d_{p}
$$

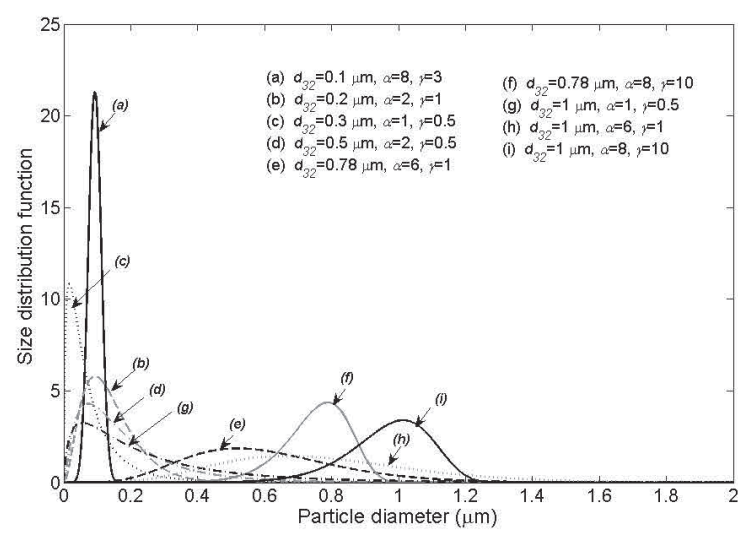

Fig. 11 Size distribution function of different polydisperse $\mathrm{TiO}_{2}$ 


\section{5. 解析結果}

ナノ粒子として JR-800 を用いた機能膜の解析結果と実 験結果の比較を Fig. 12 に示寸. Figure 12 から JR-800を用 いた Sample の解析結果と実験結果はほぼ一致しているこ とがわかる. 次に, 解析において多分散の粒径分布を与 え NIR に反射率のピークが存在するように最適粒径分布 の検討を行った. その解析結果を Fig. 13 に示寸. Figure 13 から粒径の大きさによって波長に対する反射率が変化し ていることがわかる. 特に, 大きな粒径の粒子を用いた 機能膜の NIR の反射率が小さな粒径の粒子を用いた機能 膜よりも大きくなっていることがわかる．中でも， $d_{32}=0.778 \mu \mathrm{m}$ の粒径分布では VIS の反射率が抑えられ, NIR の反射率が大きくなっていることがわかる. 特に分 布幅の小さい(f)が NIR に強いピークを持つ. このことか ら, (f)の粒径分布が波長選択性を有した機能膜の作製に 適していることを示した. しかしながら, より正確な粒 径制御を行った単分散の粒径分布を与えた解析結果 ${ }^{[3]} の$ 方でより良い反射率分布を得ている。この解析法は他の 粒子の最適粒径の算出にも適用できる.

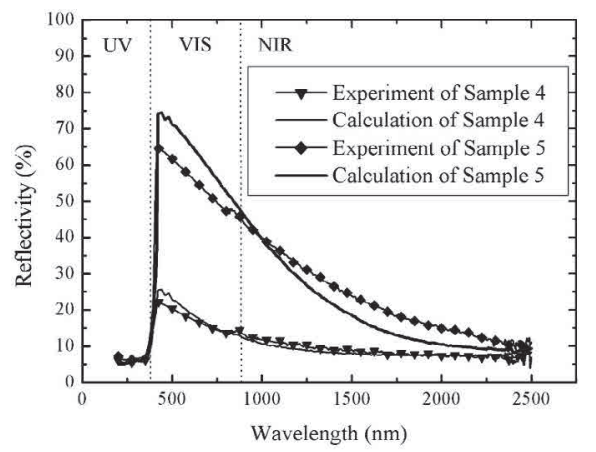

Fig. 12 Comparison between numerical and measurement result about diffuse reflectivities of $\mathrm{TiO}_{2}$ coating using JR-800

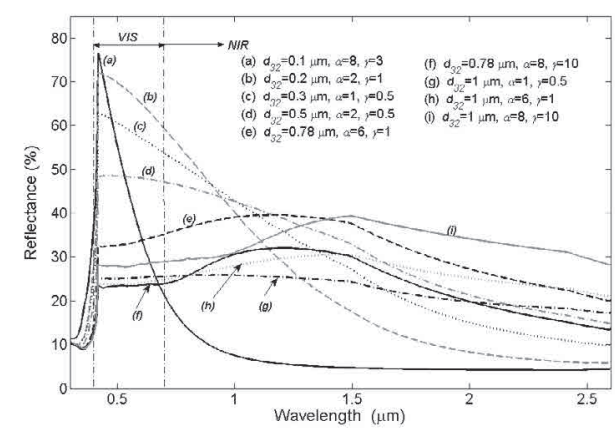

Fig. 13 The variation of spectral reflectivity with size distribution function

\section{6. 色計算}

機能膜を作成した際に，その色を定量的に評価するた め, Fig. 14 に示す C.I.E. color system ${ }^{[7]}$ を用いて色計算を行 った. C.I.E. color system とは色を明度 $Y[\%]$ と色度座標 $(x$, y)で表す体系である。明度と座標は(6)-(10)式で示される.

$$
\begin{aligned}
& X=\frac{1}{k} \int_{0.38}^{0.78} I(\lambda) \rho(\lambda) \bar{x}(\lambda) d \lambda, \\
& Y=\frac{1}{k} \int_{0.38}^{0.78} I(\lambda) \rho(\lambda) \bar{y}(\lambda) d \lambda, \\
& Z=\frac{1}{k} \int_{0.38}^{0.78} I(\lambda) \rho(\lambda) \bar{z}(\lambda) d \lambda . \\
& x=\frac{X}{X+Y+Z} \\
& y=\frac{Y}{X+Y+Z}
\end{aligned}
$$

ここで $k[-]$ は定数, $I\left[\mathrm{~W} / \mathrm{m}^{2}\right]$ は太陽放射スペクトル, $\rho[-]$ は測定した拡散反射率, $\bar{x}, \bar{y}, \bar{z}[-]$ は波長毎に決まる関数 である. 測定結果と解析結果の反射率の色計算結果を Fig. 14 に示寸. 各 Sample とも色度がほぼ一致しており, 白を 示している. VIS の反射率の特に大きかった Sample 5 の 明度は大きくなっているが，他の Sample の明度は抑えら れており, 明度を考慮しても一部の Sample は色がほとん ど変化していないと考えることができる，また，解析に おける(e),(f)も明度が抑えられている。ここから，ある色 の基板に対してその色をほとんど変えることなく反射率 が制御できることがわかる.
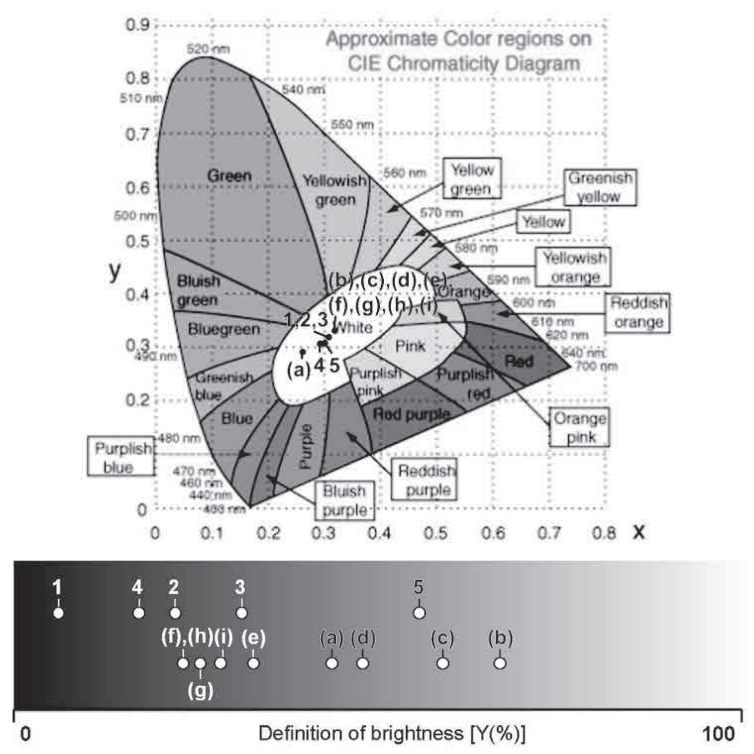

Fig. 14 C.I.E. color system ${ }^{[7]}$ and color calculation result 


\section{7. 結 言}

本研究では $\mathrm{TiO}_{2}$ ナノ粒子を用いた機能膜を作成し，そ の拡散反射率を測定した。また, 機能膜に関して理論解 析を行い, 最適な粒径分布を算出した. また, 機能膜に 関して色計算を行った. 以下に得られた知見を示す.

1. 機能膜の体積分率と膜厚が拡散反射率の大きさに影 響し, 粒子の粒径分布が拡散反射率の波長依存性に 影響することを示した。

2. 機能膜の反射率に関して理論解析を行い, 多分散の 粒径分布を与え, $d_{32}=0.778 \mu \mathrm{m}$ の粒径分布が波長選 択性を有した機能膜の作製に適していることを示し た.

3. C.I.E. color system を用いて色計算を行い, 機能膜が どのように見えるかを定量的に評価することで，色 を変えることなく反射率が制御できることを示した．

\section{参考文献}

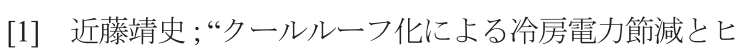
ートアイランドの緩和”, 月刊リフォーム, 10 (2008), テッアドー出版.

[2] 長岡亮介, 笠井康吉, 堀長生, 奥田章子; 「環境配 慮型太陽熱高反射率塗料の開発: その 1 熱反射性能」, 日本建築学会大会学術講演梗概集. A-1 材料施工, 2007(2007) 827-828.

[3] M. Baneshi, S. Maruyama, H. Nakai, and A. Komiya; "A new approach to optimizing pigmented coatings considering both thermal and aesthetic effects", Journal of Quantitative Spectroscopy \& Radiative Transfer, 110(2009) 192-204.

[4] 株式会社テイカ, Private Communication.

[5] S. Maruyama; "Radiative heat transfer in anisotropic scattering media with specular boundary subjected to collimated irradiation", International Journal of Heat and Mass Transfer, 41(1998) 2847-2856.

[6] Deirmendjian D; "Electromagnetic scattering on spherical polydispersions”, American Elsevier publishing company, (1969).

[7] http:/hyperphysics.phy-astr.gsu.edu/hbase/vision/cie.html

\section{NOMENCLATURE}

$a$

$a_{1}$

$b$

$d_{32}$

$d_{p}$

$f_{v}$

I

$I_{\lambda}$

$I_{b, \lambda}$

$k$

$n$

$Q_{b a c k, s c a}$

$Q_{\text {sca }}$

$S$

$T$

t

$V_{y}$

$X, Y, Z$

$x, y$

$x_{d}$

$x_{t}$

$\bar{x}, \bar{y}, \bar{z}$

$\alpha, \gamma$

$\beta$

$\Phi_{\lambda}$

$\lambda$

$\mu$

$\rho$

$\rho_{x}$

$\omega$
: constant for number density of particle, -

: forward scattering parameter, -

: constant for mean diameter of particle, -

: Sauter diameter, $\mathrm{nm}$

: particle diameter, $\mu \mathrm{m}$

: volume fraction, -

: solar irradiation spectral distribution, $\mathrm{W} / \mathrm{m}^{2}$

: radiation intensity, $\mathrm{W} / \mathrm{m}^{2} \mathrm{sr}$

: blackbody radiation intensity, $\mathrm{W} / \mathrm{m}^{2} \mathrm{sr}$

: constant for C.I.E. color system, -

: size distribution function, -

: back scattering efficiency, -

: scattering efficiency, -

: light path, $\mathrm{m}$

: temperature, $\mathrm{K}$

: film thickness, $\mu \mathrm{m}$

: volume of acryl synthetic resin, $\mathrm{m}^{3}$

: tristimulus value, -

: chromaticity coordinate, -

: coordinate, $\mathrm{m}$

: weight of $\mathrm{TiO}_{2}$, g

: spectral tristimulus value, -

: constant for size distribution function, -

: extinction coefficient, $1 / \mathrm{m}$

: phase function, -

: wavelength, $\mu \mathrm{m}$

: direction cosine, -

: reflectivity, -

: density of $\mathrm{TiO}_{2}, \mathrm{~g} / \mathrm{cm}^{3}$

: albedo, -

[Received Jun. 14, 2010, Accepted Sep. 23, 2010] 